\title{
RORAIMA: UMA ANÁLISE GEO-HISTÓRICA (DÉC. 1980 - 1990)
}

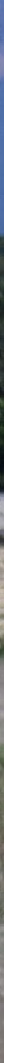

\section{RESUMO}

O presente artigo contextualiza o estado de Roraima, onde este encontra-se na porção da Amazônia Setentrional com seus limites de fronteira na porção nordeste: com a República Cooperativa da Guiana e na porção norte: com a República Bolivariana da Venezuela, e fazendo divisas, na porção sudeste e noroeste, respectivamente, com os estados do Pará e Amazonas. O trabalho tem como objetivo analisar através do recorte Geo-histórico, entre os anos de 1980 a 1990, o entendimento da formação social-política-territorial do estado. Na metodologia foram trabalhadas pesquisas bibliográficas in loco (visitas em bibliotecas públicas) e virtual (visitas em sites), visitas técnicas a órgãos governamentais, sob a luz conceitos teóricos da Geografia, bem como, a fomentação de mapas para melhorar o entendimento da territorialidade de Roraima. Nesse sentido é relevante discutir, no âmbito do saber acadêmico, produções cientificas que contextualizam os estados da Amazônia Legal.

Palavras - chave: Roraima. Sociedade. Política. Fronteira

\section{RESUMEN}

El presente artículo contextualiza el estado de Roraima, éste se encuentra en la porción de la Amazonía septentrional con sus límites de frontera en la porción noreste: con la República Cooperativa de Guyana y en la porción norte: con la República Bolivariana de Venezuela y haciendo divisas, en la porción en el sudeste y noroeste, respectivamente, con los estados de Pará y Amazonas. El trabajo tiene como objetivo analizar a través del recorte Geo-histórico, décadas de 1980 - 1990, el entendimiento de la formación social-política-territorial del estado. En la metodología se trabajaron investigaciones bibliográficas in situ (visitas en bibliotecas públicas) y virtual (visitas en sitios), visitas técnicas a órganos gubernamentales, así como, la fomentación de mapas en el entendimiento de la territorialidad de Roraima, bajo la luz epistemológica de la Ciencia geográfica. En este sentido es relevante discutir, en el ámbito del saber académico, producciones científicas que contextualizan los aspectos sociopolíticos de los estados que componen la Amazonía Legal.

Palabras clave: Roraima. Sociedad. Política. Frontera. 


\section{INTRODUÇÃO}

O Estado de Roraima encontra-se no extremo norte do território brasileiro, e estende-se em latitude $1^{\circ} 35^{\prime} 11^{\prime \prime} \mathrm{S}$ a $5^{\circ} 16^{\prime}$ $20^{\prime \prime} \mathrm{N}$ e longitude $58^{\circ} 54^{\prime} 20^{\prime \prime} \mathrm{L}$ a $64^{\circ} 49^{\prime} 18^{\prime \prime} \mathrm{O}$, o que the dar uma peculiaridade em possuir mais de $80 \%$ do seu território no hemisfério Norte. Cabe ressaltar que, nesse estado encontra-se o ponto extremo norte do Brasil (Monte Caburaí).

o estado possui uma área correspondente a $2,4 \%$ do território brasileiro e aproximadamente $6 \%$ da Região Norte. É destaque por estar, substancialmente, acima da linha do Equador e sua capital, município de Boa Vista, encontra-se totalmente, no hemisfério norte.

Ainda, em sua etimologia linguística do toponímio - Roraima - apresenta morfologicamente como derivado do termo Roro-imã, que possui diferentes significados. Nesta perspectiva, Roraima (2009) afirma que a gênese da palavra, em língua indígena Macuxi, por exemplo, significa Monte Verde e para os índios Pémon e Taurepang, quer dizer Mãe dos Ventos.

Com a criação do Estado de Roraima pela Constituição da República Federativa do Brasil - CRFB, de 1988, o território passa a fazer parte das 26 (vinte e seis) Unidades Federativas e o Distrito Federal, o que hoje representa o território brasileiro. O estado possui uma área total de $224.298,980 \mathrm{~km}$, fazendo fronteira tripartite internacional (Brasil - Venezuela - Guiana), na porção norte e noroeste; Brasil e Venezuela possuem uma fronteira com 958 km, ao leste; Brasil e Guiana com $964 \mathrm{~km}$ de fronteira, ainda limita-se com o Pará; ao Sudeste e Amazonas; ao Sul e Oeste, como mostra a Figura 01.

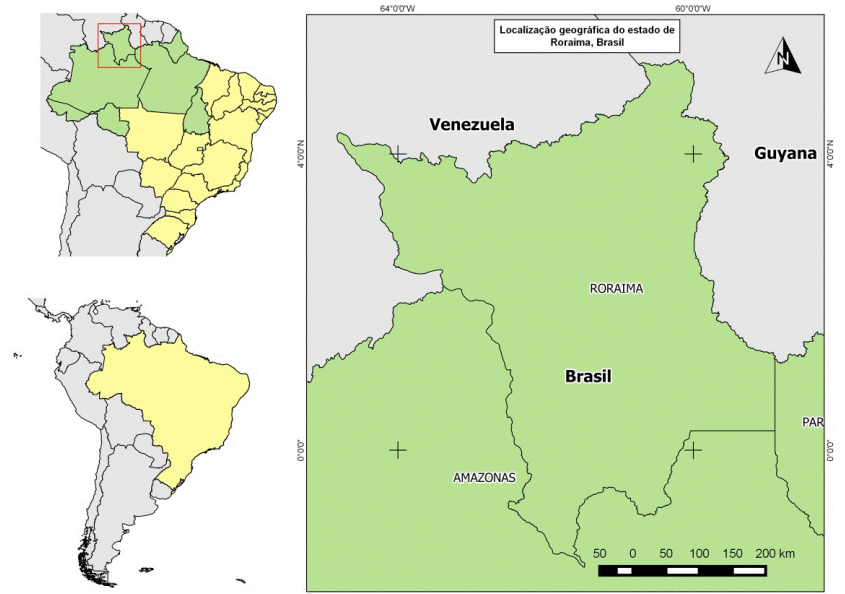

Figura 01. Localização Geográfica do Estado de Roraima. Fonte: MMA/FUNAI, 2015. Elaborada pelo Autor, 2015.

Neste sentido, este trabalho científico tem como objetivo destacar o valor Geohistórico (social - político - territorial) do Estado de Roraima, bem como compreender a política do projeto Calha Norte, seus objetivos e consequências, na região Amazônica.

\section{MATERIAIS E MÉTODOS}

O trabalho desenvolveu-se através de pesquisas bibliográficas in loco (visitas em bibliotecas públicas) e virtual (visitas em sites), bem como visitas técnicas a órgãos governamentais, a Secretaria de Estado de Planejamento e Desenvolvimento - SEPLAN/ RR e o Instituto Brasileiro de Geografia e Estatística - IBGE na aquisição de colher informações e dados sobre o tema do trabalho.

Envolveu-se a aplicabilidade de procedimentos teóricos e metodológicos diferenciados entre a Geografia e História, de forma integradora, à compreensão da configuração Geo-histórica do território com a perspectiva do entendimento das relações sociais, políticas e fronteira, onde se desenvolveram abordagens epistemológicas de caráter: i) Geo-históricos - com Silva (2007); Veras (2009); Vale (2008) e os dados do IBGE (2010/2017); SEPLAN (2010).

$\mathrm{Na}$ representação da realidade do 
território de Roraima utilizaram-se recursos técnico-metodológicos na fomentação de mapas como uso de software livre (QGis) e bases cartográficas do MMA (2015) e FUNAI (2015).

\section{RESULTADOS E DISCUSSÃO}

\section{RORAIMA: SOCIEDADE, POLÍTICA E FRONTEIRA}

O Estado de Roraima antes da CRFB/1988 era representado por oito municípios, sendo eles: Boa Vista (1890); Caracaraí (1955); Alto Alegre (1982); Mucajaí (1982); Bonfim (1982); Normandia (1982); São Luiz do Anauá (1982); São João da Baliza (1982), como apresenta a Figura 02, a seguir. nico-metodológicos na fomentação de mapas como uso de software livre (QGis) e bases cartográficas do MMA (2015) e FUNAI (2015).

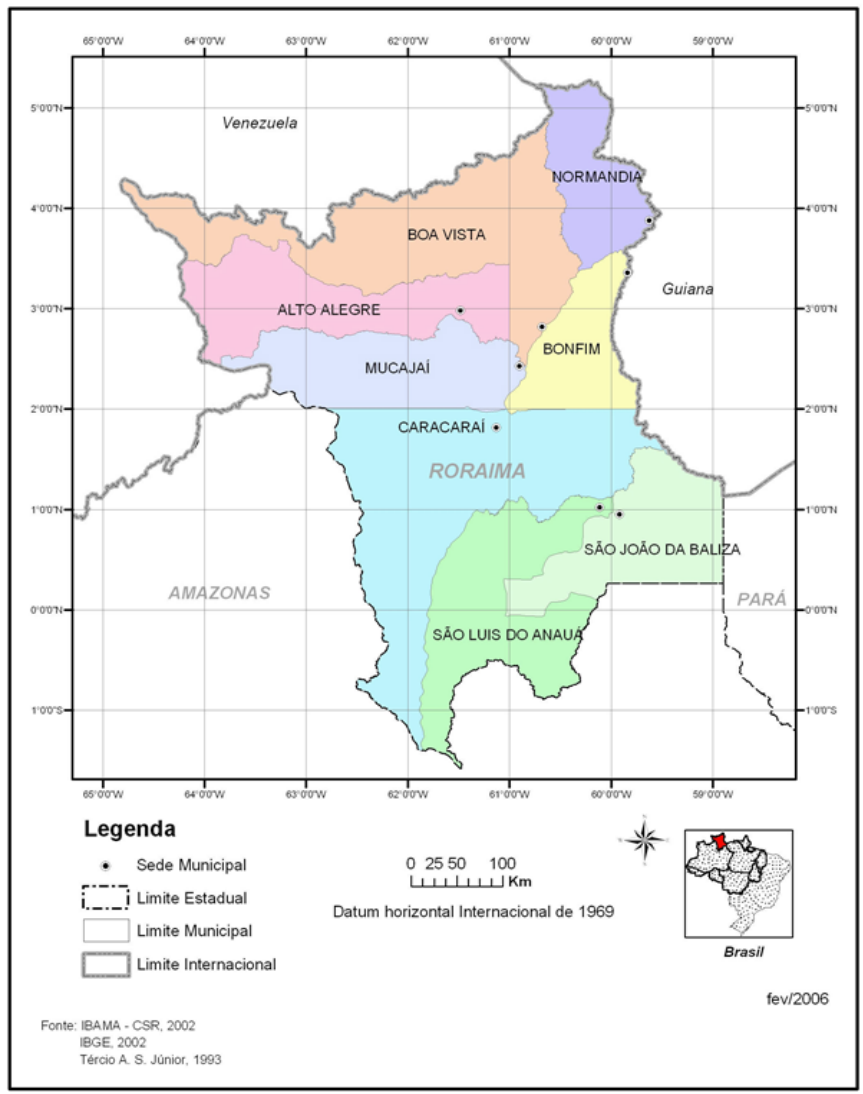

Figura 02. Divisão Político-Administrativa de Roraima, Antes da CRFB de 1988. Fonte: Silva, 2007.
Cabe ressaltar que, entre os anos de 1980 a 1991, o estado tem um crescimento populacional de $175 \%$ e isso ocorre quando os governos, Federal e Estadual, executam projetos que incentivam a ocupação e o povoamento motivados pela carência de: infraestrutura básica (saúde, educação, transporte, saneamento, comunicações, etc.); baixíssima densidade populacional permeada por imensos vazios demográficos; problemas com drogas ilícitas e contrabando; problemas com garimpos ilegais; grande parte da região com inexpressiva, ou até mesmo ausência, da presença governamental (GALDINO, 2017).

$\mathrm{O}$ reflexo desse crescimento, quantitativamente, gera um "fenômeno demográfico" marcado durante os anos de 1980 a 1991, apresentado na Tabela 01, a seguir.

\begin{tabular}{l|l|l|l}
\hline \multirow{2}{*}{$\begin{array}{l}\text { Unidades } \\
\text { políticas }\end{array}$} & \multicolumn{2}{|c|}{ População } & \multirow{2}{*}{$\begin{array}{c}\text { Crescimento } \\
\text { em (\%) }\end{array}$} \\
\cline { 2 - 3 } & \multicolumn{1}{|c|}{1980} & \multicolumn{1}{c}{1991} & \multicolumn{1}{c}{ em } \\
\hline Brasil & 119.011 .052 & 146.825 .475 & 23,37 \\
Norte & 6.619 .755 & 10.030 .556 & 51,52 \\
Roraima & 79.121 & 217.583 & 175
\end{tabular}

Tabela 01. Comparativo Populacional entre os Anos 1980 a 1991.

Fonte: IBGE, 2017. Elaborada pelo Autor, 2018.

É relevante fazer menção do Projeto de Assentamento Dirigido Anauá (PAD - Anauá), apresentaram-se resultados expressivos, no que diz respeito à ocupação/povoamento no Estado de Roraima. Cabe destacar, que entre os anos de 1981 a 1984, o Governo Federal e entidades públicas criaram um Centro de Recepção e Triagem na Vila de Jundiá (hoje município de Rorainópolis) localizado no km 330, da BR 174 (Boa Vista - Manaus) onde cadastravam, de forma aleatória, a última procedência e origem dos migrantes (VALE, 2005).

Os dados coletados nesse período informaram que: $53,6 \%$ dos migrantes eram da Região Norte; $26,7 \%$ do Nordeste; $9 \%$ do CentroOeste; $6,2 \%$ do Sul e 4,5\% do Sudeste. Sobre as maiores procedências eram, respectivamente, 
de Rondônia, do Maranhão, do Amazonas e do Pará. E quanto à origem dos migrantes foi constato que $44,3 \%$ são do Nordeste; $18,2 \%$ do Sudeste; $17,6 \%$ do Norte; $12,2 \%$ do Sul e $7,7 \%$ do Centro-Oeste (VALE, 2005).

Com os mesmos dados foi possivel identificar o destino dos migrantes que revelou os seguintes resultados: $41,9 \%$ da população migrante se dirigem para a zona urbana; $13 \%$ para a zona de garimpo; $45,1 \%$ para os projetos de assentamento agrário (VALE, 2005).

Observa-se que, um grande fluxo migratório se dirigiu para Boa Vista (capital), nos anos 80, sobretudo 1981 e 1982. A falta de infraestrutura básica, sem estradas para escoar a produtividade agrícola, gera um colapso nos assentamentos agrícolas e o resultado tem sido o êxodo rural (VALE, 2005).

Nesse período, o governo utilizou-se de uma política chamada de "paternalismo local", e iniciou a doação de lotes urbanos a população migrante e, dessa forma surgem novos bairros como: Liberdade; Buriti, Caimbé;
Asa Branca (Figura 03), além de doar materiais para construção de residências, alimentos básicos, entre outros (VALE, 2005).

O momento atual é marcado por um aumento, considerável da densidade demográfica urbana (Boa Vista), e os "novos bairros" surgem sem a mínima condição de infraestrutura básica. Porém, cabe ressaltar que, o migrante além de adquirir seu lote na área urbana também recebia outro na área rural (VERAS, 2009 \& VALE, 2005).

Na mesma década, no governo do então Presidente José Sarney fora apresentado um estudo coordenado por um Grupo de Trabalho Interministerial pela Secretaria de Planejamento e integrado por representantes dos Ministérios das Relações Exteriores, dos Ministérios Militares, hoje Ministério da Defesa e do Ministério do Interior.

Este estudo foi relevante, pois com os dados do RADAM - Brasil revelaram riquezas como: minérios (cassiterita, ferro, nióbio, zinco, manganês); metal nobre (ouro) e gema

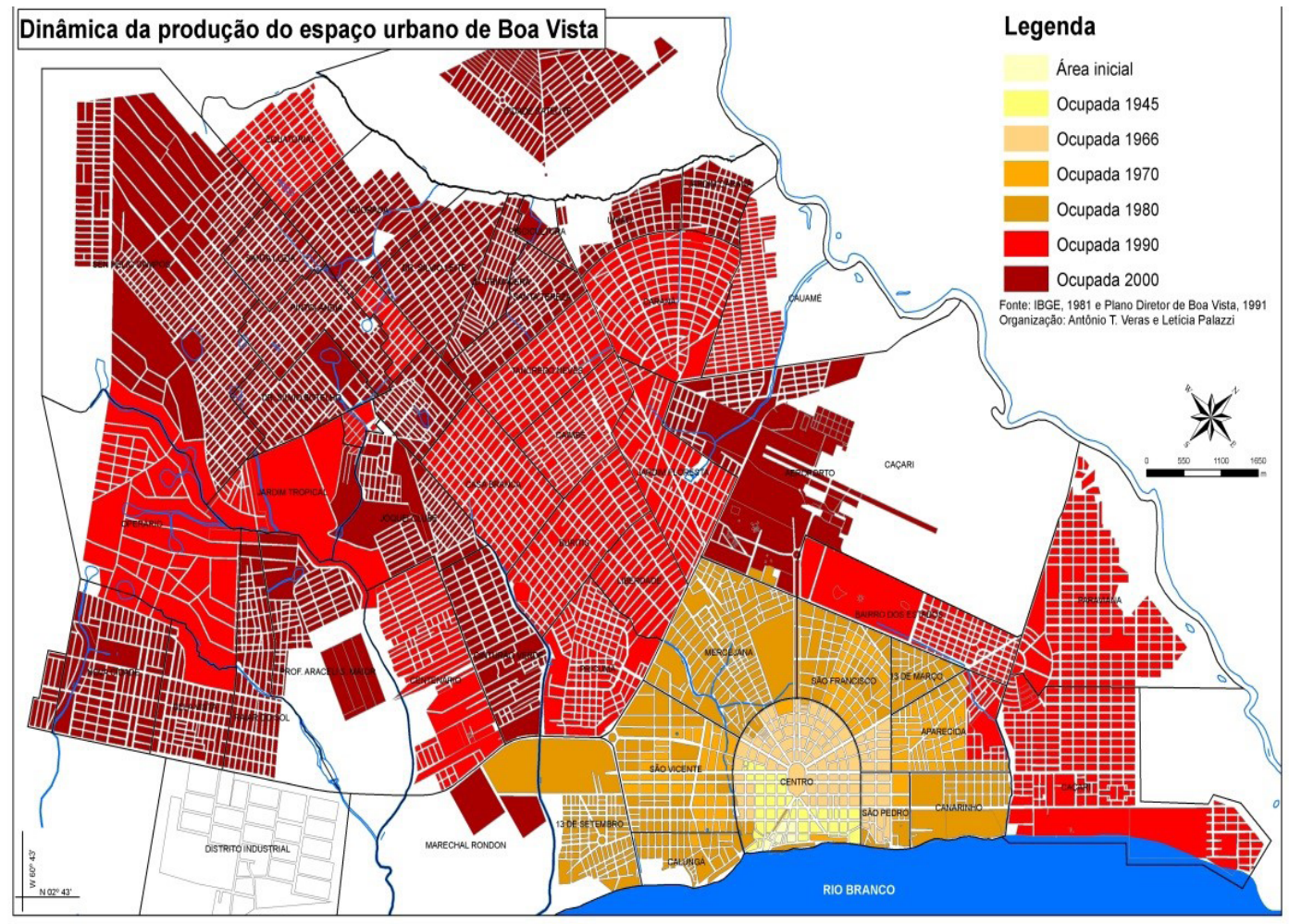

Figura 3. Dinâmica da Produção do Espaço Urbano de Boa Vista/ Plano Diretor de Boa Vista - 2006. Organização: Antonio Tolrino de Rezende Veras e Letícia Palazzi. Fonte: IBGE, 2004 apud VERAS, 2009. 
preciosa (diamante), e legitimou no Projeto de Desenvolvimento e Segurança na Região ao Norte das Calhas dos Rios Solimões e Amazonas - "Projeto Calha Norte" (Figura 04). tariamente para insumo energético de grandes indústrias do setor mineral (SILVA, 2006 apud VERAS, 2009, p. 134).

\section{ÁREA DE IMPLANTAÇÃO DO PROJETO CALHA NORTE}

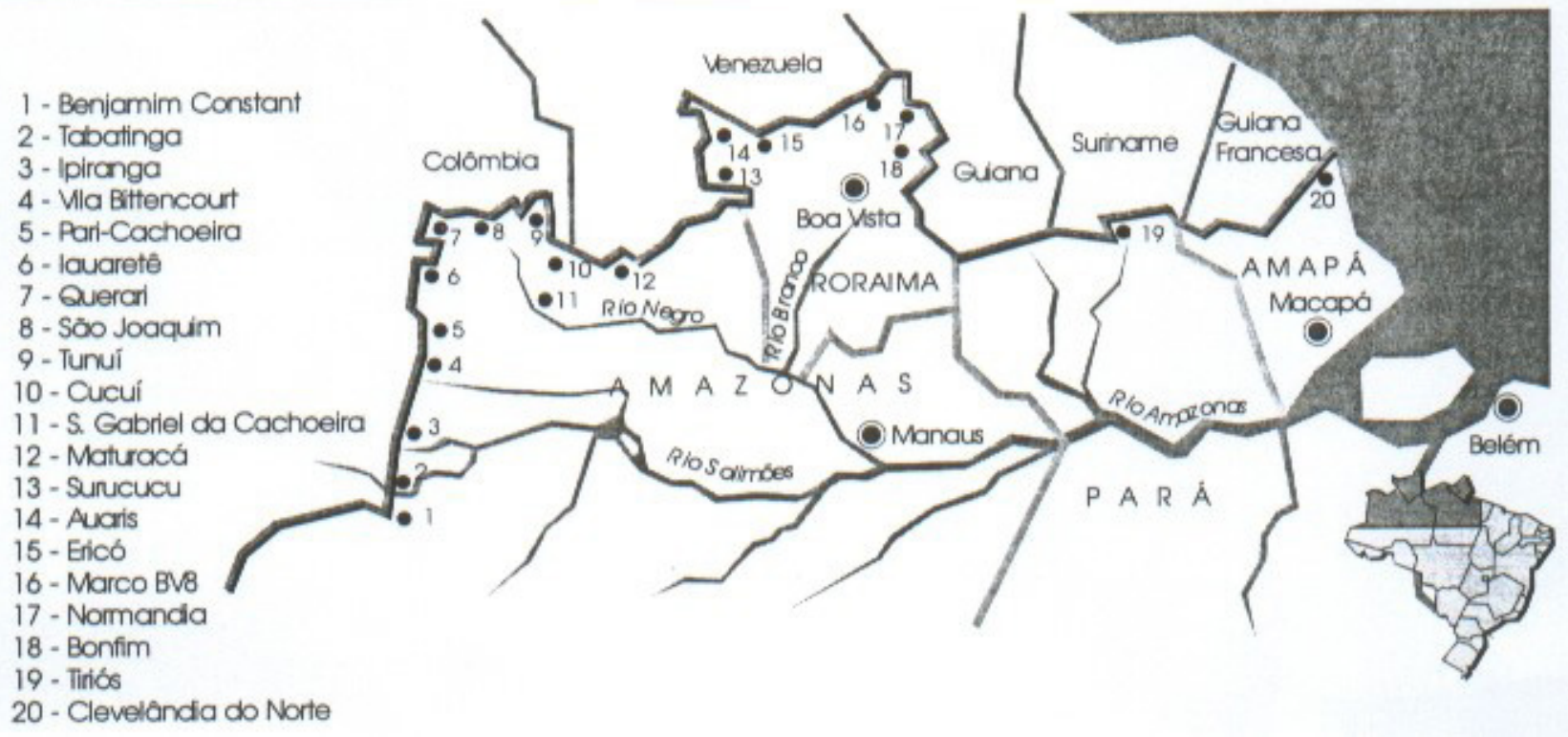

Em dezembro de 1985, o citado projeto tem início e ocorre uma mobilização de caráter estratégico com foco militar-demográficoeconômico para uma extensão da fronteira de $6.500 \mathrm{~km}$, de Tabatinga (AM) ao Oiapoque (AP), o que corresponde a umafaixa fronteiriça de $14 \%$ do território nacional, limitando-se com 05 (cinco) países: Venezuela; Colômbia; Suriname; Guiana Francesa e República Cooperativista da Guiana (VALE, 2005 \& SILVA, 2007). Ainda, corroborando, pode-se afirmar que:

[...] a estratégia de ocupação da Amazônia favoreceu a criação de mecanismos de incentivo à penetração do capital nacional e internacional no mercado de terras, assegurando vantagens fiscais para a criação de grandes projetos agropecuários. Isso atraiu trabalhadores rurais para programas de colonização dirigida, abrindo estradas e consolidando a infraestrutura de transportes, comunicações e energia elétrica, priori-
Segundo Pasa (1990) apud Vale (2005) o projeto compartilhava com os seguintes objetivos:

- Aumentar a presença de brasileiros na área de fronteira;

- Melhorar relação bilateral;

- Fiscalizar e recuperar os marcos limítrofes;

- Definir uma política indigenista apropriada à Região;

- Ampliar e melhoramento da infraestrutura viária;

- Interiorizar e acelerar os pólos de desenvolvimento econômico;

- Fortalecer a infraestrutura de energia e comunicação, insumos básicos para o desenvolvimento da região;

- Fortalecer a ação dos órgãos governamentais de Justiça, Polícia Federal, Receita Federal e Previdência Social na região, como fatores de inibição da prática de ilícitos, decorrentes da 
insuficiente presença do estado.

Com as decisões tomadas, pelo Governo Federal, na Região do Projeto Calha Norte os objetivos passam a ser seguidos e os militares conduzem uma "política de ocupação", em especial, coordenar a migração oriunda da Região Sul e Nordeste.

Nesse momento, Roraima passa a ter uma visibilidade diferenciada em relação aos outros estados que estavam inseridos no projeto, pois uma forte corrente migratória, que ali estava e que ali chegava, fez com que o Governo Federal implantasse os maiores projetos de colonização, tanto em gênero numérico como em espacialidade.

O período de 1987 a 1990, o estado é marcado por alguns fatos históricos como: a transição de território ao estado, em 1988, onde o primeiro governador eleito pela população, o Brigadeiro reformado da Aeronáutica, Ottomar de Souza Pinto que tomou posse no dia 1o de janeiro de 1991, e o outro fato é marcado, segundo vale (2005), pelo "boom garimpeiro" ou "corrida do ouro" (SILVA, 2007).

Para Barros (1995) esta fonte econômica de extrativismo mineral provocou uma dispersão da população de Boa Vista (capital) ocasionando o declínio no preço dos imóveis e centenas de habitações semi-acabadas e fechadas (VERAS, 2009).

Em 1991, com o caso do fechamento do garimpo, no Governo do Presidente Fernando Collor de Melo, a capital de Roraima vislumbra um crescimento urbano desordenado expandindo-se em direção a zona oeste e um princípio de dispersão após o rio Branco, década de 1990, com o loteamento - cidade Santa Cecília, que se tornou um bairro satélite de Boa Vista, porém localizado no município de Cantá, como mostra a Figura 05 (SILVA, 2007).
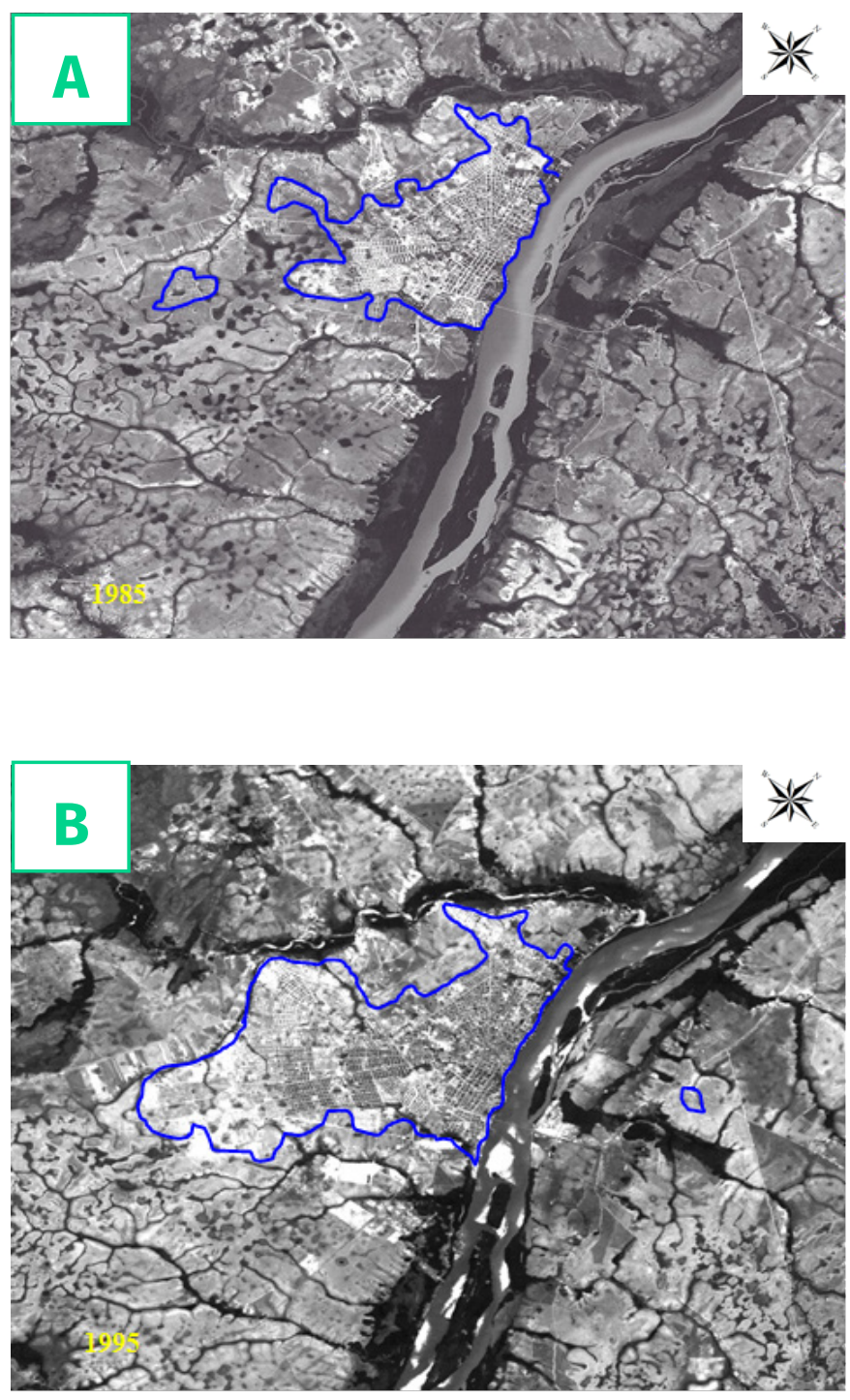

Figura 5. A) Foto de Boa Vista em 1985. B) Foto de Boa Vista em 1995.

Fonte: Acervo de Jaime de Agostinho apud SILVA, 2007.

Nesta perspectiva, a população do estado de Roraima cresce e como consequência novos municípios surgem durante década de 1990, fruto de uma década anterior caracterizada pelo "boom demográfico" (19801991) com $175 \%$ de crescimento populacional, em apenas 11 (onze) anos. Desta forma, revelase a evolução demográfica e o surgimento dos municípios em Roraima a partir da escala temporal observada na Tabela 02, a seguir. 


\begin{tabular}{|c|c|c|c|c|}
\hline Década & População de Roraima & Crescimento \% & Município & $\begin{array}{c}\text { Ano da Criação / } \\
\text { Emancipação }\end{array}$ \\
\hline 1890 & $\begin{array}{l}\text { Aproximadamente } \\
1.000^{*}\end{array}$ & & Boa Vista & $1890^{* *}$ \\
\hline 1950 & 18.116 & $\begin{array}{c}(1890-1950) \\
1.711,6 \%\end{array}$ & Caracaraí & $1955^{\star * *}$ \\
\hline 1960 & 28.871 & $\begin{array}{c}(1950-1960) \\
59,36 \%\end{array}$ & - & - \\
\hline 1970 & 40.885 & $\begin{array}{c}(1960-1970) \\
41,61 \%\end{array}$ & - & - \\
\hline 1980 & 79.121 & $\begin{array}{c}(1970-1980) \\
93,52 \%\end{array}$ & $\begin{array}{c}\text { Alto Alegre } \\
\text { Mucajaí } \\
\text { Bonfim } \\
\text { Normandia } \\
\text { São Luiz do Anauá } \\
\text { São João da Baliza }\end{array}$ & $1982^{\star \star *}$ \\
\hline 1991 & 217.583 & $\begin{array}{c}(1980-1991) \\
175 \%\end{array}$ & $\begin{array}{c}\text { Iracema } \\
\text { Caroebe } \\
\text { Amajari } \\
\text { Uiramutã } \\
\text { Pacaraima } \\
\text { Rorainópoles } \\
\text { Cantá }\end{array}$ & $\begin{array}{l}1994^{* * * *} \\
1994^{* * * *} \\
1995^{* * * *} \\
1995^{* * * *} \\
1995^{* * * *} \\
1995^{* * * *} \\
1995^{* * * *}\end{array}$ \\
\hline 2000 & 324.397 & $\begin{array}{l}(1991-2000) \\
49,09 \%\end{array}$ & - & - \\
\hline 2010 & 450.479 & $\begin{array}{c}(2000-2010) \\
38,86 \%\end{array}$ & - & - \\
\hline 2017 & $522.636^{* \star * * *}$ & $\begin{array}{c}(2010-2017) \\
16,01 \%\end{array}$ & - & - \\
\hline
\end{tabular}

Tabela 02. Evolução Demográfica e Surgimento dos Municípios em Roraima. Fonte: BARBOSA, 1993; IBGE, 2018; SEPLAN-RR, 2013; SILVA, 2007. Elaborada por Galdino, 2018. OBS.: * Dado extraído BARBOSA, 1993 / ** Como parte do Estado do Amazonas / *** Como Território Federal / **** Como Estado / ***** Dado estimado pelo site do IBGE em 03.03.2018.

Nos anos 1990, o surgimento/ emancipação de sete municípios em Roraima, são eles: Iracema (1994); Caroebe (1994); Amajari (1995); Uiramutã (1995); Pacaraima (1995); Rorainópolis (1995) e Cantá (1995) potencializam o crescimento da população do estado que ao longo das décadas cresce vertiginosamente com relação à média nacional.

Nessa dinâmica/evolução, de ocupação/povoamento das terras de Roraima configurou-se na criação/emancipação dos municípios de (Figura 06) e criando uma nova roupagem na divisão territorial do estado e sua capital se expande em termos espaciais e populacionais, onde segundo IBGE (2010) encontra-se 284.313 habitantes, o que corresponde a $63,11 \%$ da população roraimense. 

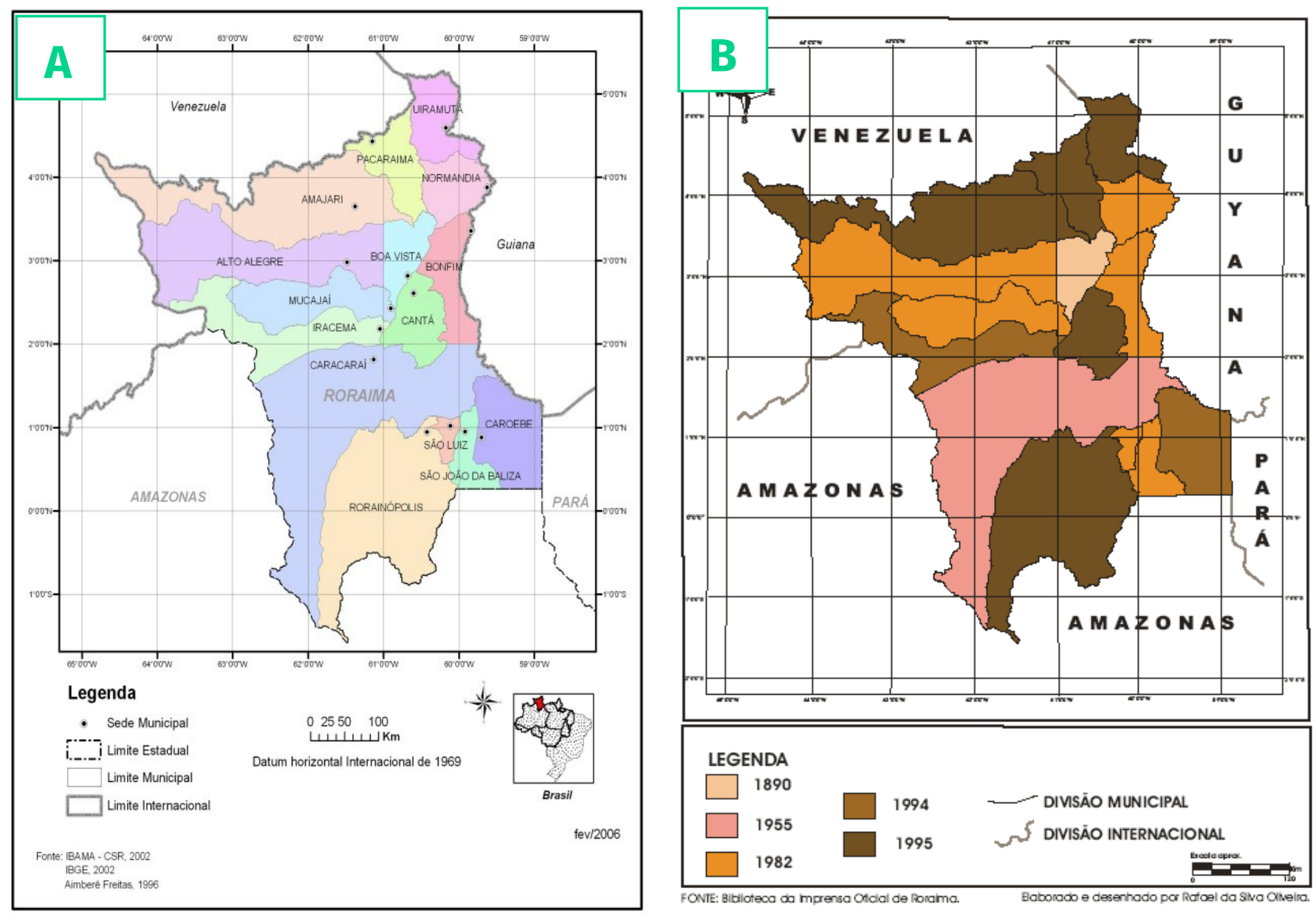

Figura 6. A) Mapa de Roraima e os Limites Municipais. B) Mapa do Período das Emancipações dos Municípios de Roraima. Fonte: Silva, 2007.

Portanto, é relevante destacar o contexto espacial, político, fronteiriços e principalmente, o social que deixou o legado da força de trabalho de migrantes e indígenas, atores símbolos da história de um estado recente e dependente, dos repasses financeiros do Governo Federal, porém uma terra rica de cultura e, principalmente, dos seus recursos naturais.

\section{CONSIDERAÇÕES FINAIS}

O presente trabalho apresentou um estudo integrado relacionado entre as Ciências, História e Geografia. Estas, alinhadas e conjuntas, desempenham um papel relevante para entender o passado e promover a compreensão, no presente, da atual conjuntura social, política e territorial do estado Roraima.

Cabe frisar que foi relevante utilizar a interdisciplinaridade dessas Ciências, no intuito de entender e fomentar um pensamento que se liga aos fatos, e ao mesmo tempo constrói a percepção de espaçotempo, trabalhado na Geografia, na utilização de tabela e figuras (mapas e fotos). Segundo Moraes, “[...] a geografia é uma espécie de ante-ato da história, um mundo de plena naturalidade, a partir do qual (e na relação com o qual) os grupos humanos vão construir suas culturas" (2005, p. 22).

Neste contexto, a Geografia apresentase como "mola-mestre" que articula os 
saberes de outras ciências e toma para si a responsabilidade de analisar, perceber e entender a dinâmica espacial que envolve as manifestações/transformações que estão entrelaçadas na construção da relação espaçotempo, o que reflete no contexto sociopolítico da sociedade.

Por fim, este artigo teve a incumbência de apresentar a riqueza histórica da sociedade e política, através do recorte espaçotemporal, de um Estado "novo" (recente) que possui um símbolo histórico-cultural, a representatividade da força indigena roraimense, e dos migrantes, principalmente, nordestinos que chegaram ao território, na missão de desenvolvê-lo.

\section{REFERÊNCIAS}

BARBOSA, R. I. Ocupação humana em Roraima I: do histórico colonial ao início do Assentamento Dirigido. Boletim do Museu Paraense Emilio Goeldi, 9 (1): 123-144. Belém, 1993-1.

BARROS, N.C.C.Paisagense Tempona Amazônia Setentrional: estudo de ocupação pioneira na América do Sul. Editora Universitária - UFPE. 1995.

GALDINO, L. K. A. Sociedade, política, cultura e meio ambiente: subsídios ao planejamento socioambiental à comunidade Boca da Mata, na Terra Indígena São Marcos - Roraima. 2017. 205 f. Tese (Doutorado em Geografia Programa de pós-graduação em Geografia), Universidade Federal do Ceará, Fortaleza, 2017.

GALDINO, L. K. A. Roraima: Sociedade, política e meio ambiente. Boa Vista: UERR, 2018.

INSTITUTO BRASILEIRO DE GEOGRAFIA E ESTATÍSTICA - IBGE. Censo de 2010/2017. Disponivel em <www.ibge.gov.br>. Acesso em: 05 abr. 2018.
RORAIMA. Guia turístico Roraima: ecológico, histórico e cultural. São Paulo: Empresa das Artes, 2009.

SECRETARIA DE ESTADO DE PLANEJAMENTO E DESENVOLVIMENTO - SEPLAN. Panorama e vetores de desenvolvimento de Roraima: Volume IIII - turismo, meio ambiente, zoneamento e recursos naturais. Boa Vista: SEPLAN, 2013.

SILVA, P. R. F. Dinâmica territorial urbana em Roraima - Brasil. 2007. 329 f. Tese (Doutorado em Geografía - Programa de Pós-Graduação em Geografia Humana), Universidade de São Paulo, São Paulo, 2007.

VALE, A. L. F. 0 "Ceará" em Roraima: migrações de cearenses - 1980 a 1999. Jaboticabal: Funep, 2005.

VERAS, A. T. R.A produção do espaço urbano de Boa Vista - Roraima. 2009. 235 f. Tese (Doutorado em Geografia - Programa de Pós-Graduação em Geografia Humana), Universidade de São Paulo, São Paulo, 2009. 